\title{
AVALIAÇÃO DE SUSTENTABILIDADE NA AGRICULTURA FAMILIAR: seleção e análise bibliométrica de publicações nacionais
}

\author{
Sustainability Assessment $\mathrm{nn}$ Family Agriculture: Selection and Analysis of \\ National Publications Bibliometric \\ Evaluación de la Sostenibilidad en la Agricultura Familiar: Selección y \\ Análisis De Publicaciones Nacionales Bibliométrico
}

MARIVÂNIA
RUFATO DA
SILVA
Professora de
Ciências
Contábeis UTFPR
WILSON ITAMAR
GODOY
UTFPR
SANDRO CESAR
BORTOLUZZI
UTFPR

Submetido em
02.06.2015.
Aprovado em
31.05.2016
Avaliado pelo
processo de
double blind
review.

review.

\section{RESUMO}

Este trabalho tem como objetivo selecionar um portfólio bibliográfico de artigos científicos nacionais com tema da avaliação de sustentabilidade na agricultura familiar e apresentar um panorama sobre estas publicações. Para atingir o objetivo proposto foi selecionado por meio de processo estruturado um portfólio bibliográfico composto por 21 publicações e organizado três bases de dados para a análise bibliométrica: (i) o portfólio bibliográfico; (ii) os artigos que constavam nas referências bibliográficas dos mesmos; e (iii) o cruzamento dos artigos do portfólio com os artigos constantes nas suas referências. Como principais resultados obteve-se que: (i) a Revista de Economia e Sociologia Rural é um periódico de destaque no portfólio e nas referências; (ii) o artigo intitulado "Sustentabilidade dos Assentamentos no Município de Caucaia-CE" é destaque no portfólio bibliográfico e seu autor Ahmad Saeed Khan é destaque nas referências; (iii) a autora Eunice Maia Andrade é destaque no portfólio bibliográfico e nas suas referências.

Palavras-chave: Avaliação de Sustentabilidade; Agricultura Familiar; Bibliometria.

\section{ABSTRACT}

This paper aims to select a bibliographic portfolio of national scientific articles with issue of sustainability evaluation in family farming and present an overview of these publications. To achieve the proposed objective was selected through process structured a bibliographic portfolio of 21 publications and organized three databases for the bibliometric analysis: (i) the bibliographic portfolio; (li) Articles which appeared in the references thereof; and (iii) the crossing of the articles of the portfolio with the relevant articles in their references. The main results were obtained that: (i) the Journal of Economics and Rural Sociology is a leading journal in the portfolio and references; (ii) the article entitled "Sustainability of Settlements in the Municipality of Caucaia-CE" is featured in the bibliographic portfolio and its author Ahmad Saeed Khan is featured in the references; (iii) the Eunice Maia Andrade author is featured in the bibliographic portfolio and its references

Keywords: Sustainability Evaluation; Family Farming; Bibliometrics.

\section{RESUMEN}

Este trabajo tiene como objetivo seleccionar una cartera bibliográfica de artículos científicos nacionales con emisión evaluación de la sostenibilidad en la agricultura familiar y presentar una visión general de estas publicaciones. Para lograr el objetivo propuesto fue seleccionado a través de una cartera proceso bibliográfica estructurada de 21 publicaciones y organizado tres bases de datos para el análisis bibliométrico: (i) la cartera bibliográfica; (li) los artículos que aparecieron en las referencias de los mismos; y (iii) el cruce de los artículos de la cartera con los artículos pertinentes de sus referencias. Se obtuvieron los principales resultados que: (i) la Revista de 
Economía y Sociología Rural es una revista líder en la cartera y referencias; (ii) el artículo titulado "La Sostenibilidad de los Asentamientos en el Municipio de CaucaiaCE" se ofrece en la cartera bibliográfica y su autor Ahmad Saeed Khan se ofrece en las referencias; (iii) el autor Eunice Maia Andrade aparece en la cartera bibliográfica y sus referencias.

Palabras clave: Evaluación de la Sostenibilidad; Agricultura Familiar; Bibliometría. 


\section{INTRODUÇÃO}

O processo de globalização e a influência crescente das tecnologias geraram várias mudanças na organização produtiva mundial. Especialmente no setor agrícola destacam-se críticas ao padrão tecnológico dominante e a exclusão de imensas regiões produtoras feita pelas grandes cadeias agroalimentares que monopolizam a produção e comércio em escala global (SCHNEIDER, 2004).

Caporal (2011) coloca que a Revolução Verde foi lançada com a intenção de resolver o problema da fome do mundo por meio de inúmeras mudanças no processo produtivo buscando aumentar a produtividade, entretanto o objetivo posto foi frustrado. Por ter o foco em apenas alguns cultivos e somente em alguns locais do planeta, esse modelo resultou no aumento da desigualdade social e no agravamento de muitos problemas ambientais.

Neste contexto, marcado pela crise relacionada ao modelo de desenvolvimento adotado, surge a noção de sustentabilidade e o conceito de que o desenvolvimento para ser sustentável deve compatibilizar crescimento econômico com preocupações sociais e ambientais (RAYNAUT, 2004; SACHS, 2001).

Para viabilizar as mudanças necessárias ao desenvolvimento sustentável, especialmente no meio rural, os processos para avaliação da sustentabilidade assumem importante papel, visto que a gestão de informações por meio de indicadores torna possível subsidiar decisões e ações dos atores envolvidos (GOMES e MALHEIROS, 2012).

Entretanto, estruturar um processo de avaliação de sustentabilidade é um objetivo complexo e várias pesquisas apontam que a noção de desenvolvimento sustentável apresenta muitas ambiguidades de interpretação em função de quem a utiliza e de onde se situa (RAYNAUT, 2004; COSTABEBER e CAPORAL, 2003).

Este fato evidencia a importância de que pesquisadores do tema compreendam como a sustentabilidade tem sido abordada na literatura, quais as diferentes concepções e que autores estão alinhados a cada uma delas. Para que seja construído esse conhecimento faz-se necessário buscar a literatura que trata do tema e é relevante que se tenha um processo estruturado para tal.

Com base nesse contexto, esta pesquisa tem como objetivo selecionar um portfólio bibliográfico de artigos científicos nacionais com tema da avaliação de sustentabilidade na agricultura familiar e apresentar um panorama sobre estas publicações.

Para o panorama proposto, será utilizada a análise bibliométrica como metodologia que baseia-se na quantificação e descrição dos elementos constitutivos da produção científica para identificar particularidades (KOBASHI e SANTOS, 2008).

Quanto à relevância, esta pesquisa justifica-se por contribuir com a comunidade científica ao apresentar um processo estruturado de seleção e análise de artigos nacionais, que neste caso possuem como tema a avaliação de sustentabilidade na agricultura familiar, mas que pode ser adaptado para outros temas. Contribui também por apresentar nos resultados da análise bibliométrica um panorama das pesquisas com informações relevantes a estudantes e pesquisadores do tema.

\section{AGRICULTURA FAMILIAR E SUSTENTABILIDADE}

No Brasil, principalmente depois da década de 90, um conjunto de transformações suscitou discussões sobre o modelo de desenvolvimento rural adotado: (i) no âmbito do 
Estado entrou em vigor a nova constituição; (ii) na sociedade civil voltaram os movimentos sociais reprimidos durante a ditadura, como as organizações não-governamentais (ONGs), associações e cooperativas; e (iii) na percepção de pesquisadores e intelectuais foram fortalecidas as preocupações com o meio ambiente e com o desenvolvimento rural sustentável (SCHNEIDER, 2010).

Baseados em resultados de muitas pesquisas, diversos autores afirmam que a agricultura familiar seria o cenário mais favorável ao desenvolvimento rural sustentável (COSTABEBER e CAPORAL, 2003; VEIGA, 1996).

Para Silva (2007, p. 20) a "agricultura sustentável é aquela capaz de manter a sua produtividade e utilidade para a sociedade, ser economicamente viável, comercialmente competitiva, ambientalmente aceitável e socialmente justa". O autor afirma que o desenvolvimento rural sustentável ainda é considerado um desafio para o setor da agricultura e que deve buscar além do crescimento econômico, a conservação e melhoria da capacidade produtiva dos solos, o melhor aproveitamento dos demais recursos com o menor impacto ambiental possível.

Bianchini (2005) coloca que o desenvolvimento rural sustentável deveria: (i) no campo ecológico, ter efeitos negativos mínimos no meio ambiente, preservar a fertilidade do solo, manter a estabilidade das reservas de água, valorizar e conservar a diversidade biológica; (ii) no campo social, valorizar o saber local e o potencial endógeno da comunidade, ter eqüidade no acesso a tecnologias; e (iii) no campo econômico, garantir a reprodução das populações locais, a qualidade de vida e um sistema agroalimentar sustentável em todos os níveis.

Costabeber e Caporal (2003) apresentam três estratégias para o desenvolvimento rural sustentável, sendo: (i) opção pela agricultura familiar; (ii) busca de novas formas de comercialização; e, (iii) dimensão local do desenvolvimento.

Para os autores a agricultura familiar apresenta vantagens econômicas, sociais e ambientais frente a outras formas de exploração, pois conta com diversidade de cultivos, eficiência produtiva e energética, proteção da biodiversidade e dos recursos naturais não renováveis, manejo meticuloso e atividades de menor impacto ambiental e com maior relevância social. Desta forma é colocada como a primeira estratégia a ser adotada.

Quanto à comercialização, Costabeber e Caporal (2003) destacam que as ações devem incorporar o fato de a agricultura familiar ter uso mais intensivo de mão de obra, mas com estilo mais poupador de insumos e menos agressivo ao ambiente. Assim deve-se estabelecer redes de confiança com o mercado consumidor que demanda produtos com essas características, focar os circuitos curtos de mercadorias com venda no mercado local e ainda apostar no consumo institucional como creches, escolas, etc.

Ainda, de acordo com os autores, a terceira estratégia para o desenvolvimento rural sustentável é a construção de contextos de sustentabilidade a partir do local, onde o protagonismo seja exercido pelos agricultores. Neste sentido, os planos de desenvolvimento são elaborados "de baixo para cima" e para definir as estratégias municipais ou regionais de realização consideram-se as particularidades de cada comunidade dentro do nível macro.

Para Veiga (1996) no modelo familiar existe a ligação direta entre trabalho e gestão, o que facilita que as decisões sejam tomadas de acordo com as especificidades do processo produtivo, com ênfase no uso de insumos internos, na diversificação e na durabilidade dos recursos naturais. 
Desta forma, verifica-se que a agricultura familiar é considerada um lócus importante para o desenvolvimento rural sustentável, o que reitera a importância de pesquisas neste tema.

\section{METODOLOGIA DE PESQUISA}

Esta seção contempla o enquadramento metodológico da pesquisa, os procedimentos para seleção do portfólio bibliográfico e os procedimentos para a análise bibliométrica.

\subsection{Enquadramento Metodológico da Pesquisa}

Uma pesquisa descritiva segundo Gil (2002) tem como objetivo descrever as características de determinada população ou fenômeno. Neste trabalho busca-se descrever as características de artigos científicos nacionais que tem como tema a avaliação de sustentabilidade na agricultura familiar.

Quanto aos procedimentos técnicos esta pesquisa caracteriza-se como bibliográfica, pois tem como base de estudo material já publicado, no caso, um portfólio bibliográfico composto por artigos científicos de periódicos nacionais classificados de $\mathrm{A} 1$ a $\mathrm{B} 5$ na área de Planejamento Urbano e Regional/Demografia da CAPES (GIL, 2002).

Em relação à abordagem do problema o método é qualitativo e quantitativo (RICHARDSON, 2008). Qualitativo no momento de seleção do portfólio bibliográfico no qual é considerada a subjetividade inerente ao processo e quantitativo na análise bibliométrica onde são utilizadas técnicas de tabulação e contagem para descrever as características do portfólio bibliográfico.

\subsection{Procedimentos para Seleção do Portfólio Bibliográfico}

Para atender aos objetivos desta pesquisa, uma das etapas é a seleção de um portfólio bibliográfico que será o objeto de estudo. Assim nesta subseção é descrito o processo estruturado para busca de artigos que têm como tema a avaliação de sustentabilidade na agricultura familiar.

A primeira etapa neste processo foi quanto à base de dados de periódicos, onde selecionou-se a área de Planejamento Urbano e Regional/Demografia da CAPES (Coordenação de Aperfeiçoamento de Pessoal de Nível Superior). No site da CAPES a lista da área citada contava com 1.120 periódicos, porém na pesquisa foram utilizados apenas os periódicos que pontuam, ou seja, fez-se a exclusão de 121 periódicos com estrato $C$. Ainda, por focar em publicações nacionais, fez-se a exclusão de 346 periódicos internacionais, restando uma amostra de 653 periódicos.

Para efetuar a seleção dos artigos foi acessado o site de cada periódico e nos que apresentavam a ferramenta de pesquisa com as expressões booleanas (and/or, e/ou), buscaram-se todos os artigos publicados que contivessem no título ou no resumo a combinação de palavras: avaliação e sustentabilidade; avaliação e sustentável; mensuração e sustentabilidade; mensuração e sustentável; indicadores e sustentabilidade; indicadores e sustentável; índices e sustentabilidade e índices e sustentável. Neste processo foram encontrados 667 artigos.

A próxima etapa consistiu na leitura dos títulos dos trabalhos para verificar quais estavam alinhados ao tema da sustentabilidade no meio rural, sendo que após a leitura e 
exclusões restaram 228 artigos. Na sequência realizou-se processo de verificação do alinhamento dos 228 artigos ao tema da pesquisa pela leitura dos resumos de cada um, restando 90 artigos. Finalmente, a última etapa do processo de seleção consiste na leitura completa dos 90 artigos com vistas a manter os trabalhos que tratam a avaliação de sustentabilidade na agricultura familiar. Após a leitura completa restaram 21 artigos que compõem o portfólio bibliográfico, e são objeto da bibliometria.

\subsection{Procedimentos para a Análise Bibliométrica}

Nesta pesquisa a análise bibliométrica apresenta uma visão das publicações nacionais relacionadas ao tema "avaliação de sustentabilidade na agricultura familiar". Neste sentido, para abordar uma maior extensão de trabalhos relacionados ao tema, optou-se pela análise bibliométrica dos artigos do portfólio bibliográfico e dos artigos científicos constantes nas referências destes. Para a pesquisa nas referências bibliográficas dos artigos foram extraídas as informações completas (autor, artigo e periódico) dos 100 artigos nacionais e internacionais citados.

Salienta-se que assim organizadas as origens, definiu-se três bases de dados para a bibliometria: (i) o portfólio bibliográfico composto de 21 artigos; (ii) os artigos que constam nas referências bibliográficas dos mesmos, sendo 100 publicações; e (iii) o cruzamento dos artigos do portfólio com os artigos constantes nas suas referências totalizando 121 trabalhos.

Nestas bases, busca-se por meio dos indicadores evidenciar quatro aspectos: (i) o grau de relevância dos periódicos; (ii) o reconhecimento científico dos artigos; (iii) o grau de relevância dos autores; e (iv) as palavras-chave mais utilizadas.

\section{RESULTADOS E DISCUSSÕES}

Neste trabalho a análise bibliométrica buscou gerar informações sobre pesquisas de avaliação de sustentabilidade na agricultura familiar. Assim, apresenta-se na sequência um panorama para cada base de dados.

\subsection{Bibliometria dos Artigos que compõem o Portfólio Bibliográfico}

Para analisar a primeira base de dados, composta pelos artigos do portfólio bibliográfico, foram considerados quatro indicadores.

No primeiro indicador buscou-se verificar o grau de relevância dos periódicos por meio da quantidade de artigos publicados por cada periódico no portfólio bibliográfico, sendo apresentados no Gráfico 1. 


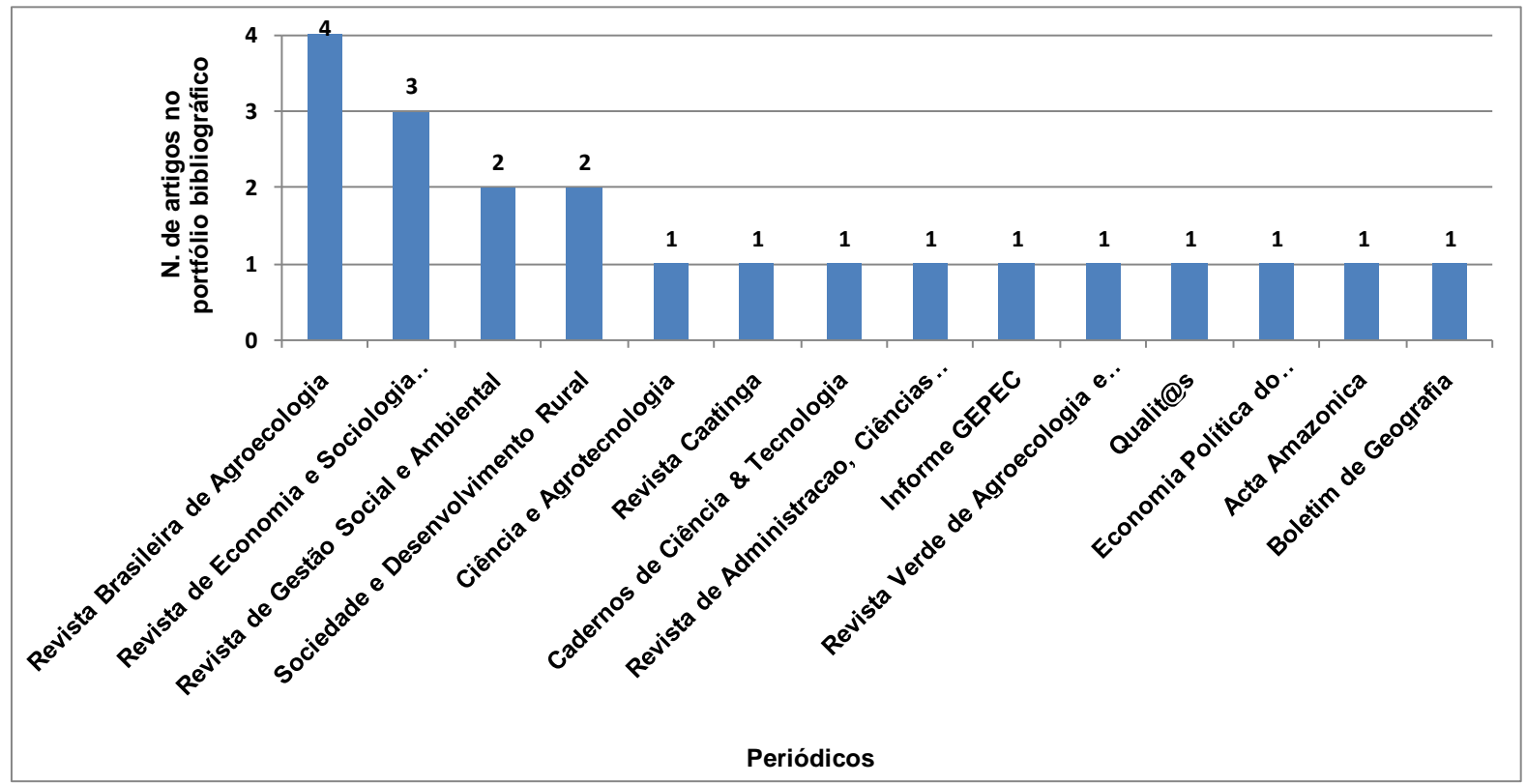

GRÁfico 1: ReleVÂNCIA dos PERIÓdICOS NO PORTFÓLIO BIBLIOGRÁFICO

Fonte: Dados da pesquisa

Percebe-se que os periódicos de maior destaque no portfólio bibliográfico são (i) Revista Brasileira de Agroecologia contendo 4 artigos; (ii) Revista de Economia e Sociologia Rural com 3 artigos; (iii) Revista de Gestão Social e Ambiental e o periódico Sociedade e Desenvolvimento Rural com 2 artigos cada. Dessa forma, pesquisadores que pretendem submeter para publicação trabalhos com tema da sustentabilidade na agricultura familiar ou que buscam publicações do assunto, podem ter como referência estes periódicos.

O segundo indicador trata do reconhecimento científico dos artigos do portfólio bibliográfico por meio da identificação da quantidade de citações dos trabalhos no Google Acadêmico. Esta verificação foi realizada no mês de abril de 2014 e no Gráfico 2 são listados os trabalhos com uma citação ou mais.

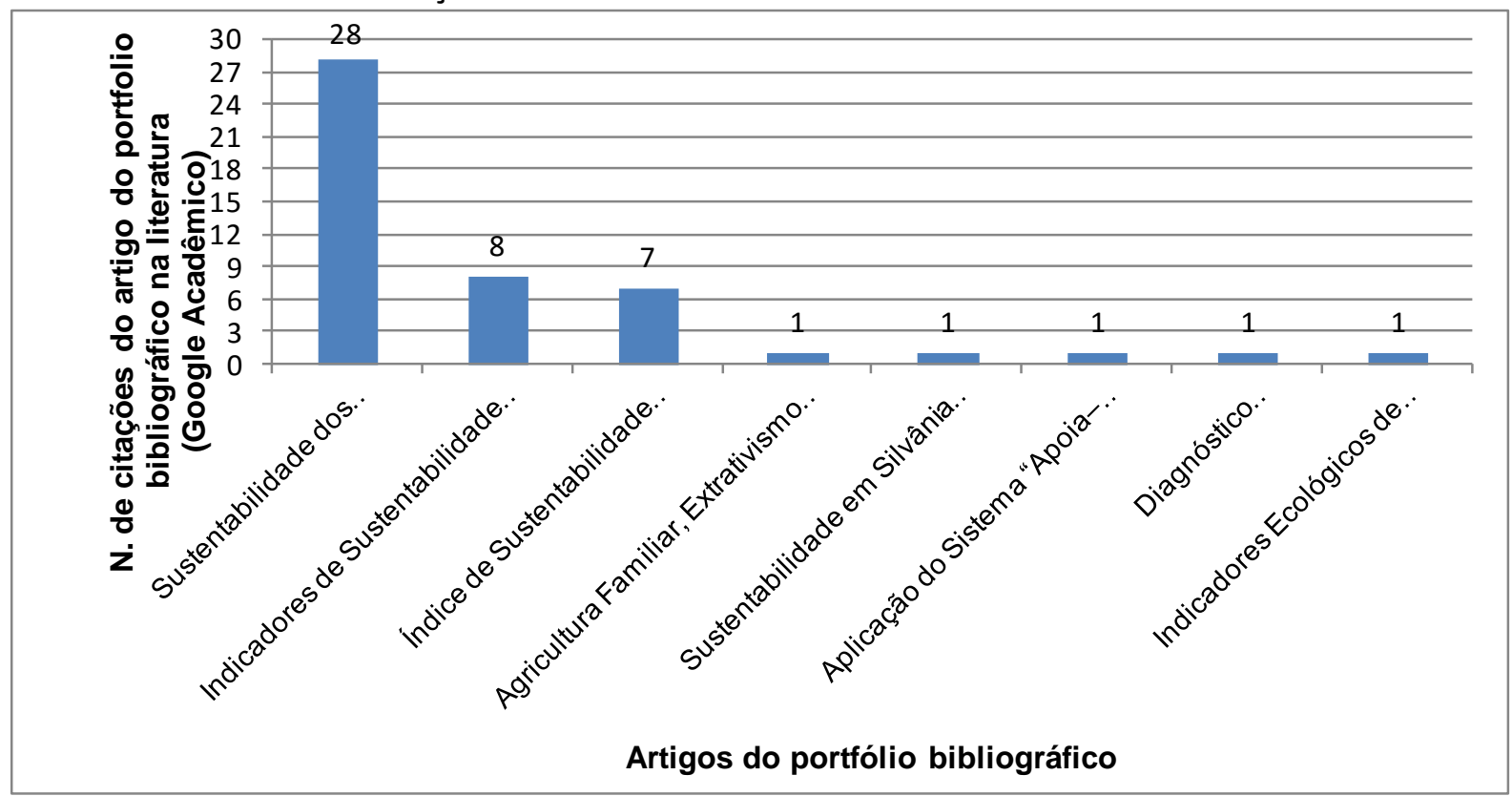

GRÁfico 2: ReCONHECIMENTO Científico dos ARTigos do PoRTFÓlio Bibliográfico

Fonte: Dados da pesquisa 
$\mathrm{O}$ artigo mais citado intitula-se "Sustentabilidade dos Assentamentos no Município de Caucaia-CE" e foi publicado no ano de 2005 na Revista de Economia e Sociologia Rural por Ricardo Candea Sá Barreto, Ahmad Saeed Khan e Patricia Verônica Pinheiro Sales Lima.

Ainda destacaram-se o artigo "Indicadores de Sustentabilidade na Reserva de Desenvolvimento Sustentável do Piranha, Manacapuru, Amazonas, Brasil" publicado em 2007 no periódico Acta Amazonica por Antonio Luiz Menezes de Andrade e o trabalho intitulado "Índice de Sustentabilidade Agroambiental para o Perímetro Irrigado Ayres de Souza" publicado no ano de 2008 por José Alves Carneiro Neto, Eunice Maia de Andrade, Morsyleide de Freitas Rosa, Francisco Suetônio Bastos Mota e José Frédson Bezerra Lopes na revista Ciência e Agrotecnologia.

Salienta-se que estes artigos possuem reconhecimento científico por já terem sido base para várias outras pesquisas, assim, podem ser considerados como referência para início de leituras sobre a sustentabilidade na agricultura familiar

$\mathrm{Na}$ terceiro indicador verificou-se a relevância dos autores de artigos do portfólio bibliográfico, sendo determinada pela quantidade de trabalhos publicados no portfólio por cada autor, conforme apresenta-se no Gráfico 3.

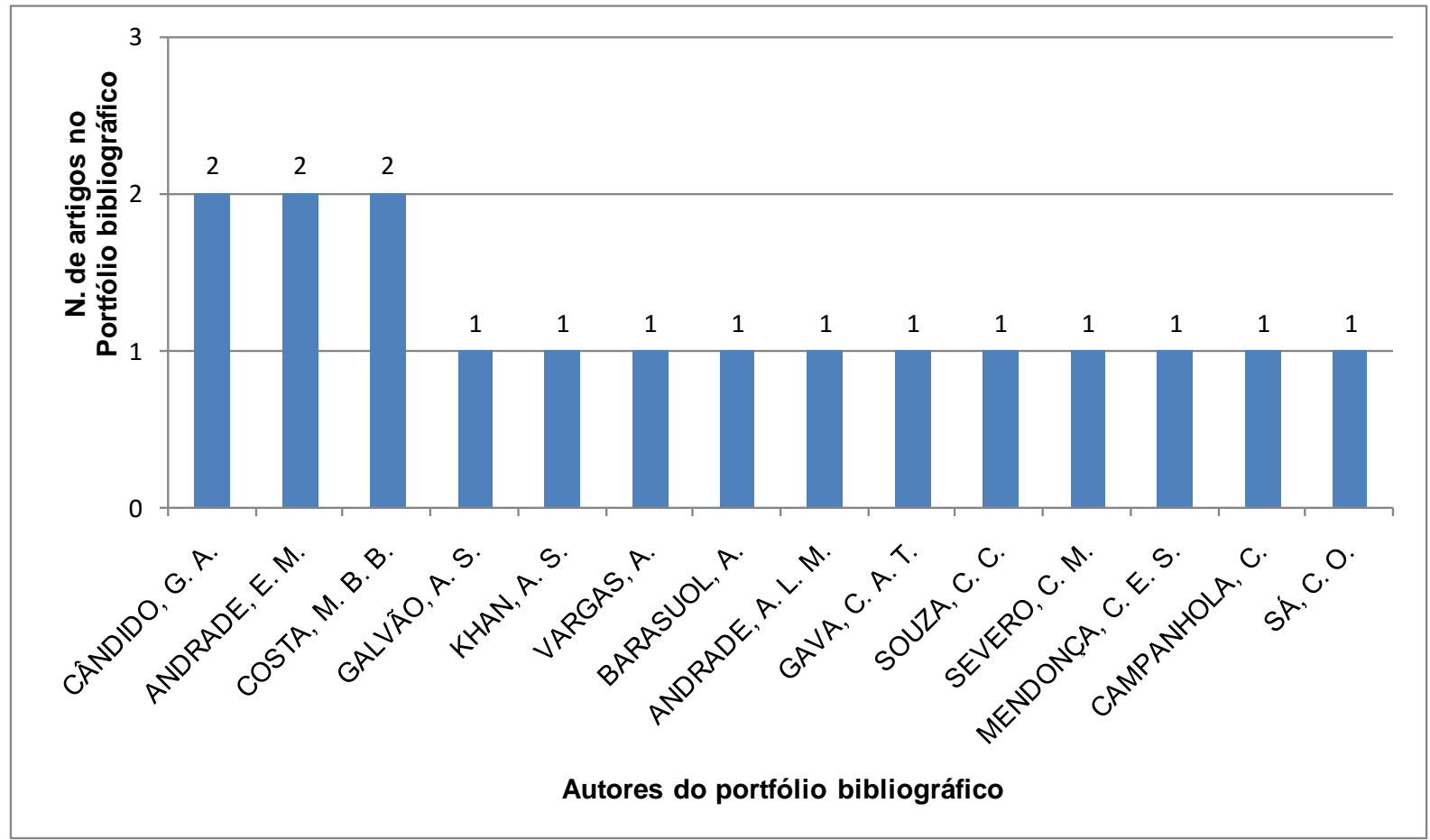

Gráfico 3: RelevÂnCia dos Autores dos Artigos do Portfólio Bibliográfico

Fonte: Dados da pesquisa

Para a elaboração do Gráfico 3 foi realizada a tabulação dos dados de autoria dos artigos, onde foram identificados 65 autores. Destes, os autores que se destacaram com dois artigos publicados no portfólio foram Gesinaldo Ataíde Cândido, Eunice Maia de Andrade e Manoel Baltasar Baptista da Costa, já os demais autores participaram com apenas um trabalho. Destaca-se que conhecer os autores de publicações nacionais relevantes sobre o tema sustentabilidade na agricultura familiar é significativo visto que pesquisando sobre os mesmos, por exemplo no Lattes, podem ser encontradas outras fontes de informações para estudo. 
Finalizando a análise dos artigos do portfólio bibliográfico buscou-se identificar as palavras-chave mais utilizadas nos trabalhos. Para isto foram extraídas as palavras-chave de cada artigo e tabulados os dados de forma a verificar as que se apresentavam com maiores repetições, sendo listadas no Gráfico 4 as palavras-chave que aparecem duas vezes ou mais nos artigos do portfólio.

Verifica-se que as palavras-chave mais utilizadas nos artigos coincidem com as palavras empregadas no processo estruturado de busca de artigos descrito na metodologia da pesquisa, principalmente os termos indicadores, sustentabilidade e sustentável.

Salienta-se que a palavra-chave que aparece mais vezes é "agricultura familiar" com 8 repetições e esta, apesar de não constar nas palavras do processo de busca, foi utilizada como filtro na seleção dos artigos no momento da leitura para que compusessem o portfólio apenas os artigos com tema de avaliação de sustentabilidade na agricultura familiar.

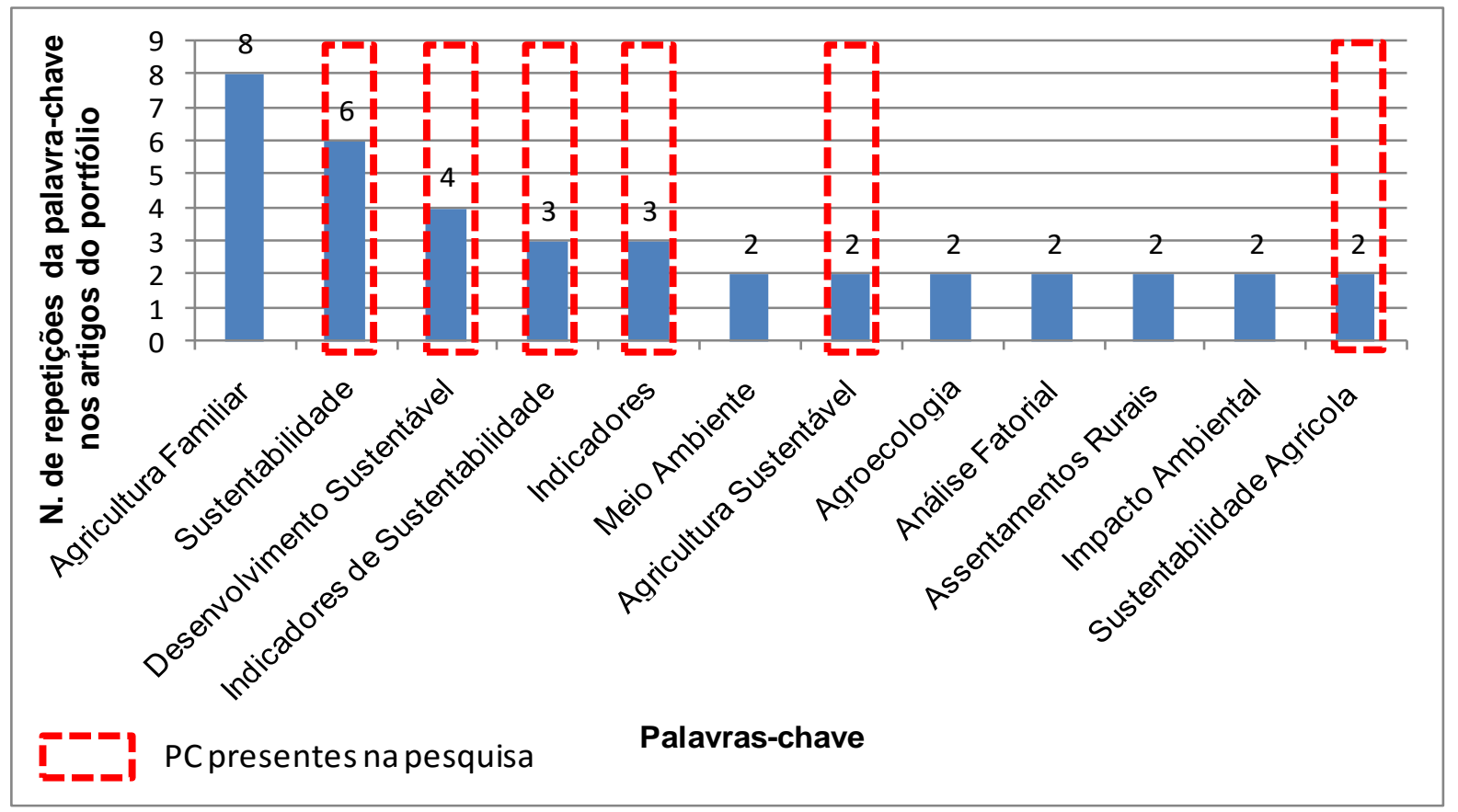

Gráfico 4: Repetições das Palavras-ChaVe dos Artigos do Portfólio Bibliográfico

Fonte: Dados da pesquisa

\subsection{Bibliometria das Referências dos Artigos que compõem o Portfólio Bibliográfico}

Para avaliar a segunda base de dados, contendo os 100 artigos das referências do portfólio bibliográfico têm-se três indicadores. O primeiro trata da relevância dos periódicos listados nas referências dos artigos do portfólio, identificada por meio da quantidade de artigos que cada periódico tinha publicado nas mesmas. 


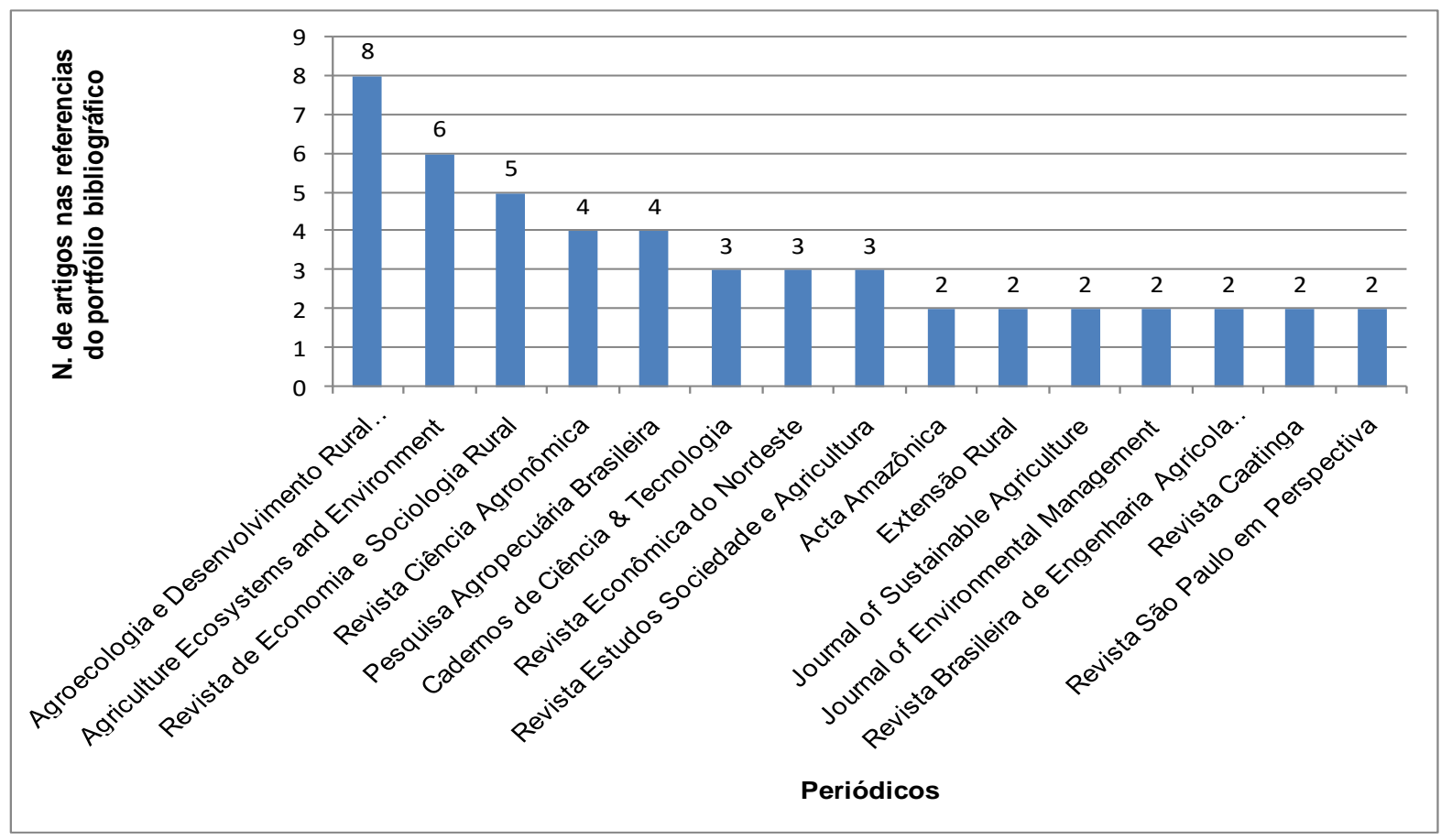

Gráfico 5: ReleVÂNCIA dos Periódicos nas ReferênCIAS dos ARTIgos no PoRTfólio Bibliográfico Fonte: Dados da pesquisa

No Gráfico 5 estão listados apenas os periódicos que contaram com mais de um artigo nas referências, onde destacaram-se as revistas Agroecologia e Desenvolvimento Rural Sustentável com 8 artigos, a Agriculture Ecosystems and Environment com 6 e a Revista de Economia e Sociologia Rural com 5 artigos. Salienta-se que os dois periódicos nacionais se destacaram na análise do portfólio bibliográfico e também nas referências deste. Ainda, verifica-se a participação relevante de um periódico internacional nas referências de trabalhos relacionados a sustentabilidade na agricultura familiar.

No segundo indicador, quanto ao reconhecimento científico dos artigos, mantevese o foco nos artigos do portfólio bibliográfico, mas agora buscando quantas vezes cada artigo do portfólio é citado entre as referências. Neste aspecto, dois trabalhos do portfólio foram citados nas referências bibliográficas, sendo o artigo intitulado Índice de Sustentabilidade Agroambiental para o Perímetro Irrigado Ayres de Souza e ainda o artigo Sustentabilidade dos Assentamentos no Município de Caucaia-CE, ambos com uma única aparição.

O terceiro indicador trata da relevância dos autores que aparecem nas referências dos artigos do portfólio bibliográfico, verificada por meio da quantidade de participações de cada um. No total identificaram-se 204 autores para os 100 artigos que constam nas referências, sendo que no Gráfico 6 listam-se apenas os autores que participaram com dois artigos ou mais. 


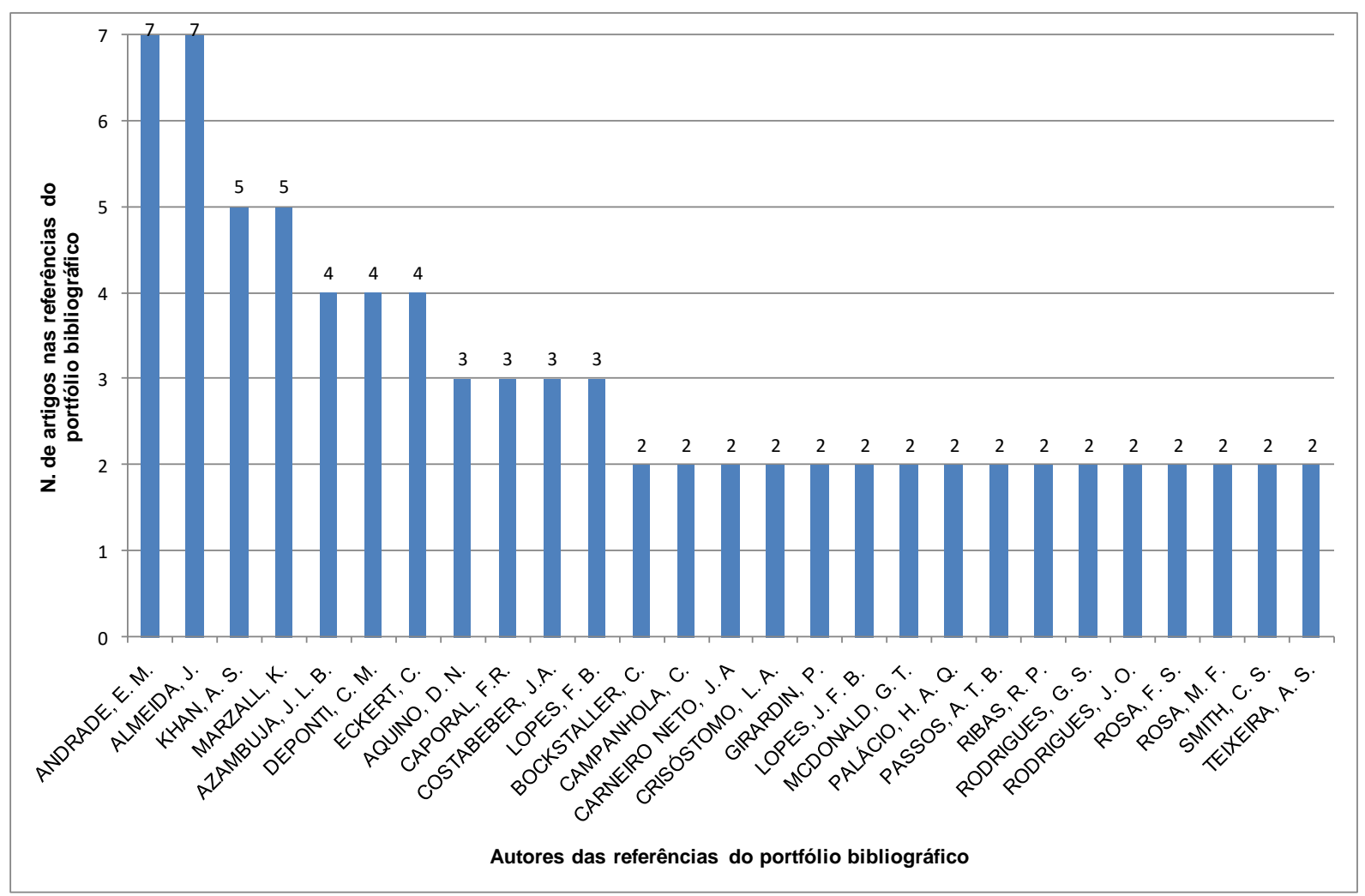

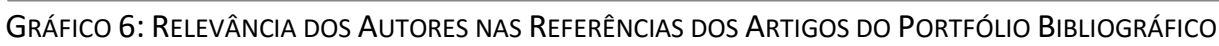

Fonte: Dados da pesquisa

Os autores que mais se destacaram nas referências dos artigos do portfólio bibliográfico foram Eunice Maia Andrade e Jalcione Almeida com autoria de sete artigos, e ainda Ahmad Saeed Khan e Kátia Marzall com cinco artigos.

\subsection{Bibliometria do Cruzamento entre os Artigos e as Referências dos Artigos que compõem o Portfólio Bibliográfico}

Quanto à terceira base de dados, utilizam-se três indicadores que cruzam as informações do portfólio e de suas referências com vistas a identificar periódicos, artigos e autores que se destacam nas duas bases.

O primeiro indicador avalia a quantidade de artigos do portfólio e artigos das suas referências publicados em cada periódico. No Gráfico 7 apresenta-se uma análise dos periódicos do portfólio bibliográfico, onde no eixo das ordenadas tem-se a quantidade de artigos que o periódico contém no portfólio bibliográfico e no eixo das abscissas a quantidade de artigos que o periódico contém nas referências do portfólio bibliográfico. Adicionalmente foi dividido o gráfico com uma linha horizontal com objetivo de separar os periódicos de acordo com a relevância no portfólio bibliográfico e outra vertical para separar os periódicos de acordo com a relevância nas referências. 


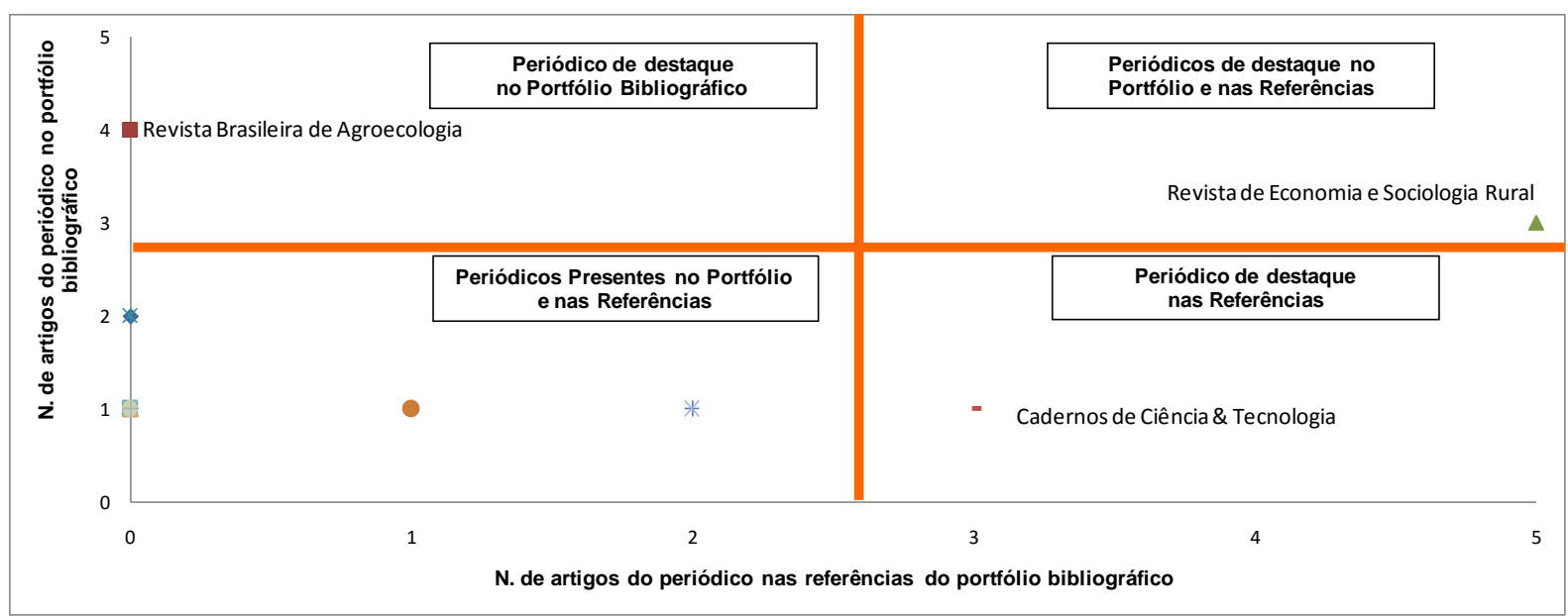

Gráfico 7: Periódicos de Destaque do PoRTfólio Bibliográfico

Fonte: Dados da pesquisa

O Gráfico 7 revela nos quadrantes os periódicos do portfólio bibliográfico de acordo com sua relevância. O quadrante de maior relevância é o que contém os "Periódicos de Destaque no Portfólio e nas Referências" onde encontra-se a Revista de Economia e Sociologia Rural com 3 artigos no portfólio bibliográfico e 5 nas referências. Já no quadrante "Periódico de Destaque no Portfólio Bibliográfico" está a Revista Brasileira de Agroecologia com 4 artigos no portfólio bibliográfico mas nenhum nas referências. No Quadrante "Periódico de Destaque nas Referências" tem-se a revista Cadernos de Ciência \& Tecnologia que faz parte do portfólio com 1 artigo, mas destacou-se apenas nas referências bibliográficas do mesmo com 3 trabalhos. Os demais periódicos que apresentam artigos no portfólio bibliográfico encontram-se no quadrante "Periódicos Presentes no Portfólio e nas Referências".

O segundo indicador contém uma análise cruzada dos artigos e autores do portfólio bibliográfico de maior destaque. No Gráfico 8 tem-se no eixo das ordenadas a quantidade de citações dos artigos do portfólio no Google Acadêmico, e no eixo das abscissas a quantidade de citações do autor mais citado do artigo do portfólio nas referências. 


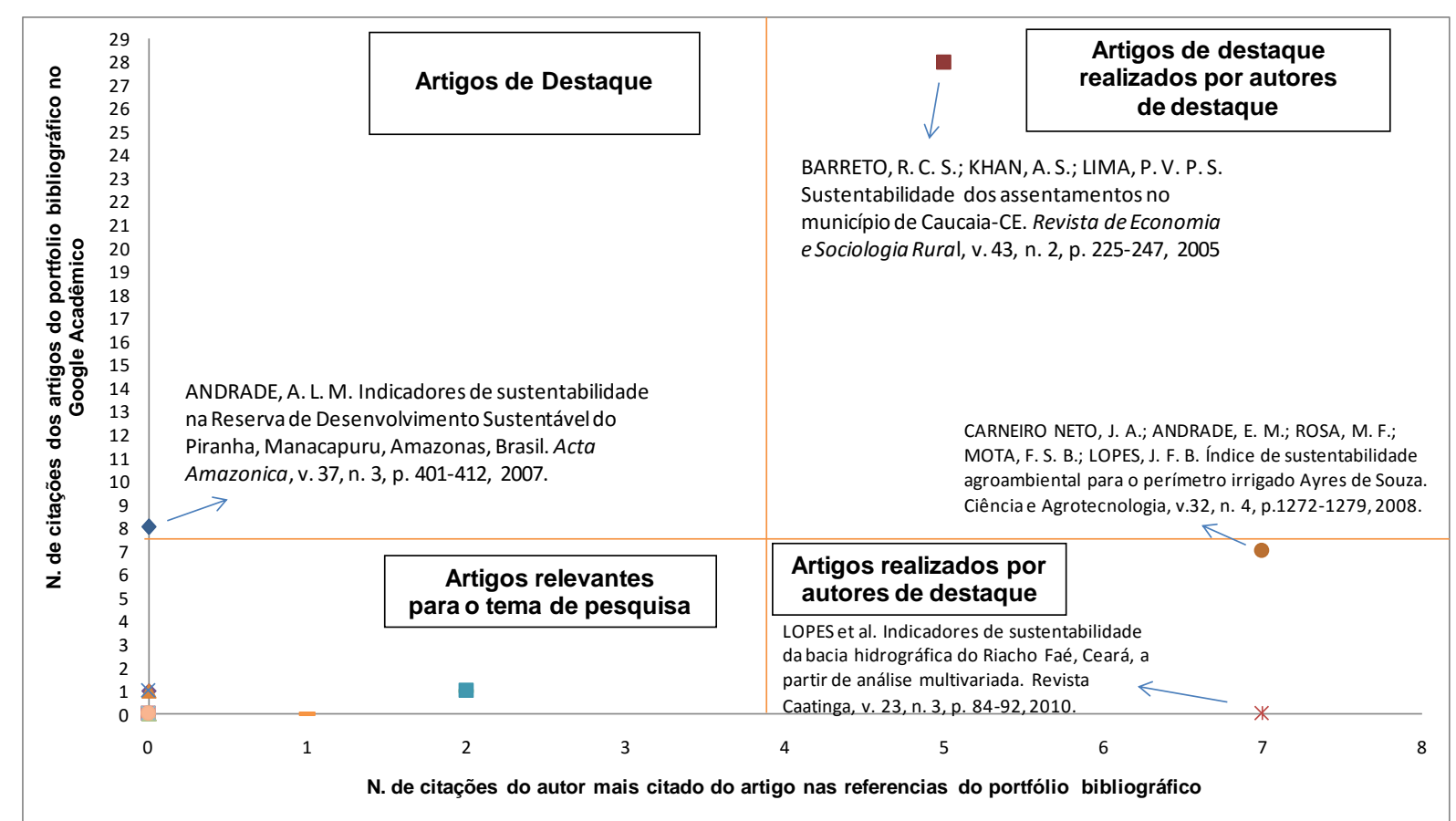

Gráfico 8: Artigos e Autores de Destaque do Portfólio Bibliográfico

Fonte: Dados da pesquisa

Verifica-se que o quadrante de maior relevância é o que traz os "Artigos de Destaque Realizados por Autores de Destaque", onde neste caso encaixa-se o trabalho intitulado Sustentabilidade dos Assentamentos no Município de Caucaia-CE. O destaque se deve ao reconhecimento científico do artigo, com 28 citações no Google Acadêmico, e pela relevância de seu autor Ahmad Saeed Khan com 5 citações nas referências do portfólio bibliográfico. No quadrante "Artigos de Destaque" encontra-se o trabalho Indicadores de Sustentabilidade na Reserva de Desenvolvimento Sustentável do Piranha, Manacapuru, Amazonas, Brasil, com 8 citações do artigo no Google Acadêmico mas onde nenhum dos autores apresentou citações nas referências do portfólio bibliográfico. Já no quadrante "Artigos Realizados por Autores de Destaque" tem-se dois trabalhos que foram realizados por autores que se destacaram nas referências do portfólio bibliográfico com 7 citações, mas onde o artigo não tem quantidade relevante de citações no Google Acadêmico. Finalmente no quadrante "Artigos Relevantes para o Tema de Pesquisa" encontram-se os outros artigos do portfólio bibliográfico e suas quantidades de citações.

Para o terceiro indicador, apresenta-se no Gráfico 9 as informações dos autores mais relevantes para o tema de acordo com a quantidade de artigos que cada autor do portfólio bibliográfico apresenta no portfólio, listada no eixo das ordenadas, e a quantidade de artigos nas referências constante no eixo das abscissas. 


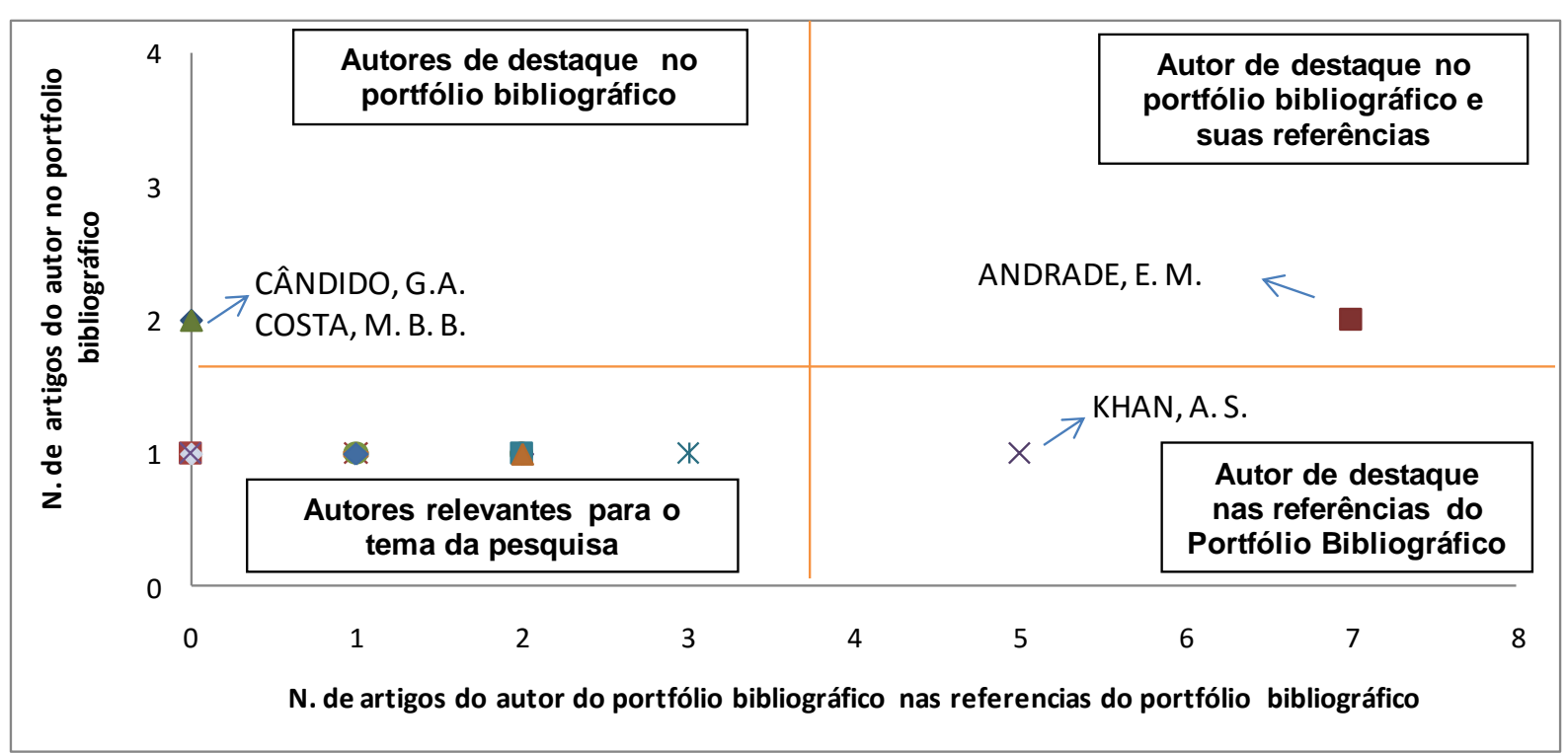

Gráfico 9: Autores de Destaque do PoRtFólio Bibliográfico

Fonte: Dados da pesquisa

A autora Eunice Maia Andrade aparece no quadrante "Autor de Destaque no Portfólio Bibliográfico e suas Referências" sendo considerada a mais relevante por contar com 2 artigos no portfólio e 7 artigos nas referências. Ainda Gesinaldo Ataíde Cândido e Manoel Baltasar Baptista da Costa constam no quadrante "Autores de Destaque do Portfólio Bibliográfico" com 2 artigos cada no portfólio, mas sem participação nas referências. Já Ahmad Saeed Khan é "Autor de Destaque nas Referências do Portfólio Bibliográfico" com 5 artigos nestas e 1 artigo no portfólio. Assim os autores restantes do portfólio bibliográfico constam no quadrante "Autores Relevantes para o Tema da Pesquisa" pois, apesar de trabalharem com o tema, de acordo com os critérios de análise estabelecidos, não destacaram-se dos demais.

\section{CONSIDERAÇÕES FINAIS}

O presente trabalho teve como objetivo selecionar um portfólio bibliográfico de artigos científicos nacionais com tema da avaliação de sustentabilidade na agricultura familiar e apresentar um panorama sobre estas publicações.

Para alcançar o objetivo geral foi realizado um processo estruturado de seleção onde chegou-se a um portfólio composto por 21 artigos com o tema de avaliação de sustentabilidade na agricultura familiar. Adicionalmente, foi realizada a análise bibliométrica em três bases de dados: (i) o portfólio bibliográfico; (ii) os artigos que constavam nas referências bibliográficas dos mesmos; e (iii) ainda o cruzamento dos artigos do portfólio com os artigos constantes nas suas referências.

Quanto à primeira base de dados chegou-se ao seguinte panorama: (i) o periódico mais relevante é a Revista Brasileira de Agroecologia; (ii) o artigo com maior reconhecimento científico intitula-se "Sustentabilidade dos Assentamentos no Município de Caucaia-CE"; (iii) os autores mais relevantes foram Gesinaldo Ataíde Cândido, Eunice Maia de Andrade e Manoel Baltasar Baptista da Costa; (iv) a palavra-chave mais utilizada foi "agricultura familiar". 
Na segunda base de dados obteve-se que: (i) o periódico mais relevante é chamado Agroecologia e Desenvolvimento Rural Sustentável; (ii) os artigos com maior reconhecimento científico intitulam-se "Índice de Sustentabilidade Agroambiental para o Perímetro Irrigado Ayres de Souza" e "Sustentabilidade dos Assentamentos no Município de Caucaia-CE"; (iii) os autores mais relevantes foram Eunice Maia Andrade e Jalcione Almeida.

$\mathrm{Na}$ terceira base de dados tem-se no panorama que: (i) a Revista de Economia e Sociologia Rural é um periódico de destaque no portfólio e nas referências; (ii) o artigo intitulado "Sustentabilidade dos Assentamentos no Município de Caucaia-CE" é destaque no portfólio bibliográfico e seu autor Ahmad Saeed Khan é destaque nas referências; (iii) a autora Eunice Maia Andrade é destaque no portfólio bibliográfico e nas suas referências.

Desta forma, conclui-se que por meio da metodologia proposta foi possível atingir o objetivo de apresentar um panorama sobre as publicações nacionais selecionadas sobre o tema avaliação de sustentabilidade na agricultura familiar. Por conseguinte, os resultados obtidos corroboram com estudos anteriores que destacam a bibliometria como metodologia que permite quantificar, descrever e identificar particularidades de publicações científicas.

\section{REFERÊNCIAS}

ALVES, Luiz B.; BASTOS, Rogério P. Sustentabilidade em Silvânia (GO): o caso dos assentamentos rurais São Sebastião da Garganta e João de Deus. Revista de Economia e Sociologia Rural, v. 49, n. 2, p. 419-448, 2011.

ANDRADE, Antonio L. M. Indicadores de Sustentabilidade na Reserva de Desenvolvimento Sustentável do Piranha, Manacapuru, Amazonas, Brasil. Acta Amazonica, v. 37, n. 3, p. 401412, 2007.

BARRETO, Ricardo C. S.; KHAN, Ahmad S.; LIMA, Patricia V. P. S. Sustentabilidade dos Assentamentos no Município de Caucaia-CE. Revista de Economia e Sociologia Rural, v. 43, n. 2, p. 225-247, 2005.

BIANCHINI, Valter. Políticas Diferenciadas para a Agricultura Familiar: em busca do desenvolvimento rural sustentável. In: BOTELHO FILHO, F. B. (org). Agricultura Familiar e Desenvolvimento Territorial - contribuições ao debate. Brasília: Universidade de Brasília, Centro de Estudos Avançados Multidisciplinares, v. 5, n. 17, 2005. p. 81-98.

CAPORAL, Francisco R. Em Defesa de um Plano Nacional de Transição Agroecológica: compromisso com as atuais e nosso legado para as futuras gerações. In: Caporal, Francisco R.; Azevedo, Edisio O. (orgs.) Princípios e Perspectivas da Agroecologia. Instituto Federal de Educação, Ciência e Tecnologia do Paraná, 2011. p. 123-153.

CARNEIRO NETO, José A.; ANDRADE, Eunice M.; ROSA, Morsyleide F.; MOTA, Francisco S. B.; LOPES, José F. B. Índice de Sustentabilidade Agroambiental para o Perímetro Irrigado Ayres de Souza. Ciência e Agrotecnologia, v. 32, n. 4, p.1272-1279, 2008.

COSTABEBER, José A.; CAPORAL, Francisco R. Possibilidades e Alternativas do Desenvolvimento Rural Sustentável. In: VELA, Hugo. (Org.): Agricultura Familiar e 
Desenvolvimento Rural Sustentável no Mercosul. Santa Maria: Editora da UFSM/Pallotti, 2003. p.157-194.

ENDE, Marta V.; FERREIRA, Gabriel M. V.; ROSSÉS, Gustavo F.; STECCA, Jaime P.; MADRUGA, Lúcia R. R. G.; BARASUOL, Aline. Índices de Sustentabilidade de Projetos da Economia Solidária: o caso Esperança/Coopesperança. Revista de Gestão Social e Ambiental, v. 6, n. 3, p. 45-60, 2012.

FERREIRA, Gizelia B.; COSTA, Manoel B. B.; SILVA, Maria S. L.; MOREIRA, Márcia M.; GAVA, Carlos A. T.; CHAVES, Vanessa C.; MENDONÇA, Claudio E. S. Sustentabilidade de Agroecossistemas com Barragens Subterrâneas no Semiárido Brasileiro: a percepção dos agricultores na Paraíba. Revista Brasileira de Agroecologia, v. 6, n. 1, p. 19-36, 2011.

GAVIOLI, Felipe R. Avaliação da Sustentabilidade de Agroecossistemas Através de Indicadores em um Assentamento Rural em São Paulo. Revista Verde de Agroecologia e Desenvolvimento Sustentável, v. 6, n. 5, p. 99-110, 2011.

GIL, Antonio C. Como Elaborar Projetos de Pesquisa. 4 Edição. São Paulo: Atlas, 2002.

GOMES, Priscila R.; MALHEIROS, Tadeu F. Proposta de Análise de Indicadores Ambientais para Apoio na Discussão da Sustentabilidade. Revista Brasileira de Gestão e

Desenvolvimento Regional, v. 8, n. 2, p. 151-169, 2012.

KOBASHI, Nair Y.; SANTOS, Raimundo N. M. Arqueologia do Trabalho Imaterial: uma aplicação bibliométrica à análise de dissertações e teses. Encontros Bibli: Revista Eletrônica de Biblioteconomia e Ciência da Informação, n.o esp., 1ㅇs semestre, p. 106-115, 2008.

LIRA, Elisandra M.; GALVÃO, Adailton S.; WADT, Paulo G. S. "Sistema de Aptidão das Terras para Recuperação Ambiental" para Avaliar a Sustentabilidade de Propriedades Rurais da Amazônia. Boletim de Geografia, v. 29, n. 1, p. 31-45, 2011.

LOPES, Fernando B.; ANDRADE, Eunice M.; OLIVEIRA, Lucio J.; CANAFÍSTULA, Francisco J. F.; SOARES, Rogério B. Indicadores de Sustentabilidade da Bacia Hidrográfica do Riacho Faé, Ceará, a Partir de Análise Multivariada. Revista Caatinga, v. 23, n. 3, p. 84-92, 2010.

MELO, Luiz E. L.; CÂNDIDO, Gesinaldo A. O Uso do Método IDEA na Avaliação de Sustentabilidade da Agricultura Familiar no Município de Ceará-Mirim - RN. Revista de Administração, Contabilidade e Sustentabilidade, v. 3, n. 2, p. 1-19, 2013.

NEIVA, José L. Proposição de Indicadores de Desenvolvimento Sustentável para Assentamentos Rurais. Economia Política do Desenvolvimento, v. 1, n. 7, p. 83-106, 2010.

RAMOS FILHO, Luiz O.; RODRIGUES, Isis; FRIGHETTO, Rosa T. S.; RODRIGUES, Geraldo S.; CAMPANHOLA, Clayton; BROMBAL, José C. Aplicação do Sistema "Apoia-NovoRural" para Avaliação do Desempenho Ambiental do Agroturismo. Cadernos de Ciência \& Tecnologia, v. 21, n. 3, p. 409-423, 2004. 
RAYNAUT, Claude. Meio Ambiente e Desenvolvimento: construindo um novo campo do saber a partir da perspectiva ambiental. Desenvolvimento e Meio Ambiente, n. 10, p. 21-32, jul.-dez. 2004.

RIBAS, Rafael P.; SEVERO, Christiane M.; MIGUEL, Lovois A. Agricultura Familiar, Extrativismo e Sustentabilidade: o caso dos "samambaieiros" do litoral norte do Rio Grande do Sul. Revista de Economia e Sociologia Rural, v. 45, n. 1, p. 205-226, 2007.

RICHARDSON, Roberto J. Pesquisa Social: Métodos e Técnicas. $3^{\circ}$ Edição. São Paulo: Atlas, 2008.

SÁ, Cristiane O.; MARINHO, Glenda L. O. C.; SÁ, José L.; RONER, Marcia N. B.; NASCIMENTO, Irinéia R.; SÁ, Francielen P. Sustentabilidade dos Sistemas de Produção dos Agricultores Familiares e Produtores de Queijo em Nossa Senhora da Glória, Semiárido Sergipano. Revista Brasileira de Agroecologia, v. 7, n. 3, p. 26-39, 2012.

SACHS, Ignacy. Quo Vadis, Brasil? In: SACHS, Ignacy; WILHEIM Jorge; PINHEIRO, Paulo S. (org.). Brasil: um século de transformações. São Paulo: Companhia das Letras, 2001. p. 488501.

SANTOS, Gesmar R.; PIASENTIN, Flora B. Estado e Desenvolvimento Rural no Brasil: contradições e desafios à sustentabilidade. Sociedade e Desenvolvimento Rural, v. 4, n. 3, p. 59-79, 2010.

SANTOS, Jaqueline G.; CÂNDIDO, Gesinaldo A. Sustentabilidade e Agricultura Familiar: um estudo de caso em uma associação de agricultores rurais. Revista de Gestão Social e Ambiental, v. 7, n. 1, p. 70-86, 2013.

SCHNEIDER, Fernando; COSTA, Manoel B. B. Diagnóstico Socioeconômico, Produtivo e Ambiental dos Agroecossistemas na Microbacia Hidrográfica do Rio Pirapora - Município de Piedade/SP. Revista Brasileira de Agroecologia, v. 8, n. 1, p. 217-231, 2013.

SCHNEIDER, Sergio. A Abordagem Territorial do Desenvolvimento Rural e suas Articulações Externas. Sociologias, v. 6, n. 11, p. 88-125, 2004.

SCHNEIDER, Sergio. Situando o Desenvolvimento Rural no Brasil: o contexto e as questões em debate. Revista de Economia Política, v. 30, n. 3, p. 511-531, 2010.

SILVA, Nardel L. S. Estudo da sustentabilidade e de indicadores de desenvolvimento rural. 2007. 271 f. Tese (Doutorado em Agronomia) - Universidade Estadual de Maringá, Maringá, 2007.

SILVA, Djane F.; ARAÚJO, Lincoln E.; SOUSA, Francisco A. S. Indicadores para Algumas Dimensões da Sustentabilidade Aplicados a Propriedades Rurais dentro de Pequenas e Médias Bacias Hidrográficas. Qualit@s, v. 7, n. 1, 2008. 
THEODORO, Vanessa C. A.; CASTRO, Franciléia P.; ABURAYA, Fernando H. Indicadores Ecológicos de Sustentabilidade de Unidades de Produção Agrícola do Assentamento Facão Cáceres, MT, Brasil. Revista Brasileira de Agroecologia, v. 6, n. 3, p. 21-33, 2011.

TONIASSO, Hélia R.; SOUZA, Celso C.; BRUM, Eron; FIGUEIREDO, Regina S. Agricultura Familiar e Associativismo Rural - o caso associação harmonia de agricultura familiar de Mato Grosso do Sul e a sua sustentabilidade. Informe Gepec, v. 12, n. 2, p. 01-10, 2007

VARGAS, Alexandre. Agricultura Familiar e Sustentabilidade. Sociedade e Desenvolvimento Rural, v. 4, n. 1, p. 133-143, 2010.

VEIGA, Jose E. Agricultura Familiar e Sustentabilidade. Cadernos de Ciência \& Tecnologia, v. 13, n. 3, p. 383-404, 1996. 